\title{
SCHUSTER, Peter, Eine Stadt vor Gericht. Recht und Alltag im spätmittelalterlichen Konstanz
}

\section{Pierre Monnet}

\section{OpenEdition}

\section{Journals}

Édition électronique

URL : http://journals.openedition.org/ifha/1261

DOI : 10.4000/ifha.1261

ISSN : 2198-8943

\section{Éditeur}

IFRA - Institut franco-allemand (sciences historiques et sociales)

\section{Référence électronique}

Pierre Monnet, «SCHUSTER, Peter, Eine Stadt vor Gericht. Recht und Alltag im spätmittelalterlichen Konstanz », Revue de l'IFHA [En ligne], Date de recension, mis en ligne le 01 janvier 2001, consulté le 22 septembre 2020. URL : http://journals.openedition.org/ifha/1261 ; DOI : https://doi.org/10.4000/ifha. 1261

Ce document a été généré automatiquement le 22 septembre 2020.

(C)IFHA 


\title{
SCHUSTER, Peter, Eine Stadt vor Gericht. Recht und Alltag im spätmittelalterlichen Konstanz
}

\author{
Pierre Monnet
}

1 P.S. peut être considéré, avec Gerd Schwerhoff, comme l'un des représentants actuels de la recherche allemande en histoire anthropologique du droit et de la criminalité. On retrouve d'ailleurs ces deux auteurs dans le recueil d'études publié par Martin Dinges et Fritz Sack sur l'insécurité urbaine et recensé dans le présent Bulletin. P.S. avait déjà publié une étude sur la pratique de la paix et du règlement des conflits à partir des très riches archives judiciaires de Constance aux XIVe et XVe s. (BullMHFA, 34, 1998, p. 278-279). Ici, ce sont plus largement le prononcé des jugements et l'application des peines à Constance entre 1300 et 1500 qui sont étudiés, sur la base d'une problématique qui entend tout simplement comprendre ce que les juges urbains de la fin du Moyen Âge comprenaient par « délit », et donc retenaient dans leur conception de la « justice ». Le livre prend également en compte ce que le tribunal ne retenait pas ou bien les délits qui ne faisaient pas l'objet d'une déclaration ou d'une comparution devant les tribunaux publics, soit tout le domaine de ce que la recherche récente a baptisé d'infrajudiciaire. Sur tous ces points, l'auteur reconnaît sa dette à l'égard de l'historiographie française sur les conflits, la justice, la délinquance et la violence (Jacques Chiffoleau, Benoît Garnot, Claude Gauvard, Robert Muchembled, Xavier Rousseaux...). Quant à l'application des peines, le principal enseignement de l'ouvrage tient à la constatation suivant laquelle dans la plupart des cas la peine prononcée n'a jamais vraiment été effectuée par le condamné. Avant comme après le jugement, les tractations continuent, les arrangements par le délinquant ou sa famille sont négociés, l'intéressé quitte la ville, puis revient, effectue sa peine par bouts, reporte, fait durer parfois des années. Ce n'est donc pas seulement un décalage entre la norme et le jugement qui est constaté, mais également entre le jugement et son application. Ce propos avait déjà été développé par l'auteur lors de la rencontre franco-allemande sur la ville et le droit tenue à Göttingen en décembre 1999 (voir BullMHFA, 35, 1999, p. 73-79, actes à paraître). La justice médiévale n'était donc pas expéditive, elle ne 
fonctionnait pas de haut en bas mais dépendait de l'action même des justiciables, et l'application des peines pouvait durer des années, sans que pour autant les justiciables se plaignent des lenteurs de la justice ou crient à la mauvaise justice... Cette justice semblait parvenir à concilier combat contre le crime et flexibilité sur le fond d'une pratique orientée vers la compensation (Ausgleich) plus que vers la pénalisation brutale. Cependant, cette flexibilité ne pouvait semble-t-il fonctionner que si de temps à autre les cadres stricts de la justice exemplaire étaient rappelés. C'était le sens des exécutions capitales et P.S. montre de manière convaincante combien justice de sang et justice quotidienne sont les deux facettes d'une même pratique qui rassemble et non point sépare les juges, les plaignants et les condamnés. C'est ainsi seulement que, dans une ville comme Constance, mais la remarque vaut aussi pour les autres cités, la justice put devenir une vertu de l'exercice du pouvoir et un instrument de la construction de l'État et de l'autorité, seuls garants de l'application et de l'éventuelle diminution d'une peine sur le fond "méritée » et d'autant mieux acceptée qu'elle était prononcée par un organe perçu comme un lieu flexible de composition et non comme l'antre d'une impossible loi du talion. Dans le cadre urbain, cette justice servait dès lors moins à combattre et à punir une criminalité menaçante qu'à consolider l'exercice du pouvoir et la diffusion du système des valeurs communales. 